Synthesis, part of a Special Feature on Catastrophic Thresholds, Perspectives, Definitions, and Applications

\title{
Catastrophic Thresholds: A Synthesis of Concepts, Perspectives, and Applications
}

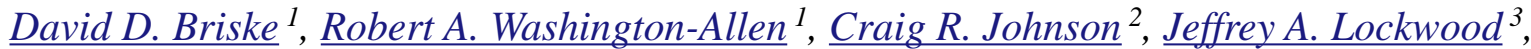 \\ Dale R. Lockwood $^{4}$, Tamzen K. Stringham ${ }^{5}$, and $\underline{\text { Herman H. Shugart }}^{6}$
}

\begin{abstract}
Research reported in this feature identifies a convergence of interpretations regarding the threshold dynamics of complex ecological systems. This convergence has arisen from a diverse set of investigations addressing rangeland ecosystem dynamics, disease transmission, and fluctuations in the populations of insect pests. Effective application of the threshold concept to ecosystem management will require development of more robust linkages between non-equilibrium theory and protocols to identify triggers that initiate threshold conditions, feedback loops that establish system resilience, and developmental trajectories and attributes of potential alternative stable states. Successful implementation of these theory/ application linkages has the potential to underpin an operational framework of resilience-based ecosystem management that is founded upon the identification of structural indicators that are correlated with vulnerability or proximity to thresholds, rather than threshold identification per se. Several investigations indicate that thresholds are strongly influenced by scale; multiple cross-scale interactions demonstrate the need for greater knowledge and analyses to address scale-dependent processes, i.e., critical scales and scaling laws. This feature emphasizes the relevance of thresholds and non-equilibrium dynamics in multiple natural resource management applications and in so doing demonstrates the need for a more comprehensive and integrated ecological framework capable of quantitatively assessing dynamics at multiple scales to inform management and policy recommendations for optimal management and risk assessment.
\end{abstract}

Key Words: complexity science, ecological resilience, non-equilibrium ecology, self-organized systems, systems theory

\section{INTRODUCTION}

The invited papers in this special feature, including those that were presented in the 2006 Ecological Society of America symposium, titled: Catastrophic Thresholds, Perspectives, Definitions, and Applications, that was sponsored by the Rangeland Ecology Section of the ESA, (Washington-Allen and Salo 2007, Washington-Allen et al. 2009: This Feature's Introduction) apply aspects of general systems theory to explain threshold behavior at several levels of ecological organization. These papers focused on the development of innovative conceptual models including, novelty (Allen and Holling 2010), the textural discontinuity hypothesis
(Wardwell and Allen, 2009), time-scale calculus (Thomas et al. 2009), threshold-based conceptual models emphasizing catastrophe theory and selforganization (Lockwood and Lockwood 2008), a nonlinear diffusion model (Ridolofi et al. 2008) and characteristics of ecological resilience (WashingtonAllen et al. 2008) to explain community, ecosystem, and landscape dynamics. Associated analytical tools including computer simulations, time-scale calculus, characteristic length scale (Johnson et al. 2008, Garmestani et al. 2009), 1/f noise and fractal analysis (Lockwood and Lockwood, 2008), classical linear stability analysis (Ridolfi et al. 2008), and satellite image differencing and time series analyses (Washington-Allen et al. 2008) were

\footnotetext{
${ }^{1}$ Department of Ecosystem Science and Management, Texas A\&M University, ${ }^{2}$ School of Zoology, University of Tasmania, ${ }^{3}$ Department of Philosophy, University of Wyoming, ${ }^{4}$ Biology Department, Colorado State University, ${ }^{5}$ Department of Animal Biotechnology, University of Nevada-Reno, ${ }^{6}$ Department of Environmental Sciences, University of Virginia
} 
used to detect both states or dynamic regimes and thresholds in space and time.

Thresholds are defined as boundaries in time and space in non-equilibrial systems that separate alternative stable states (i.e., dynamic regimes) organized around unique attractors or equilibrium points (Mayer and Rietkerk 2004, WashingtonAllen et al. 2006, 2009, Lockwood and Lockwood 2008; Fig. 1 feature introduction). The occurrence and potential consequences of thresholds have been referenced in numerous terrestrial and aquatic ecosystems (Elmqvist et al. 2003, Scheffer and Carpenter 2003, Folke et al. 2004, Scheffer 2009, authors this feature). Consequently, thresholds are of tremendous relevance to ecology and natural resource management because they signify the occurrence of substantial and potentially irreversible changes that may variously affect ecological patterns and processes and the capacity of ecosystems to continue to provision services (Gunderson 2000, Scheffer and Carpenter 2003, Scheffer 2009).

This paper synthesizes information from the contributions of this special feature to increase understanding of the concepts, perspectives and applications of ecological thresholds. We begin with a brief review of catastrophic thresholds, within the framework of non-equilibrial ecology, to provide a context to more effectively interpret the contributions within this special issue. Feature contributions have been organized into three broad themes: threshold identification and essential conditions, interpretation and mechanisms, and application to ecosystem management.

\section{THRESHOLDS: ORIGIN AND SIGNIFICANCE}

The concepts of thresholds and alternative stable states grew out of dissatisfaction with equilibrium ecology that had previously dominated ecological thought and ecosystem management (Egerton 1973, $\mathrm{Wu}$ and Loucks 1995). Equilibrium ecology is founded on the assumption that ecosystems possess the capacity for internal regulation through balancing and self-regulating feedback mechanisms (Meadows 2008), including intense intra- and interspecific competition and plant-animal interactions (O'Neill et al. 1986, Ellis and Swift 1988, Wu and Loucks 1995, Lockwood and Lockwood, 2008).
Therefore, equilibrium systems are assumed to return to their predisturbance state (i.e. homeostasis) or to their pre-disturbance trajectory (i.e. homeorhesis) when disturbance has ceased (O'Neill et al. 1986, Wu and Loucks 1995). This capacity for internal regulation is widely assumed to contribute to the predictable and directional response of equilibrium system behavior.

Criticism of equilibrial ecology began early in the $20^{\text {th }}$ century for several reasons, including (1) the dearth of evidence to support the occurrence of equilibrium systems, (2) the inability to account for the dynamic behavior of various ecological systems, and (3) the implication that historical events play only a minor role in ecosystem dynamics (O'Neill et al. 1986, Wu and Loucks 1995). However, it was not until the 1970s that the theoretical basis for ecosystem dynamics deviated from the equilibrium perspective, when several prominent ecologists promoted the existence of multiple alternative or equilibrium states (Holling 1973, May 1977). This established the basis for development of nonequilibrium ecology that was founded on the assumption that ecosystems possess a limited capacity for internal regulation (Wu and Loucks 1995). Consequently, the behavior of nonequilibrium systems is characterized as more dynamic and less predictable than equilibrium systems (Pickett and Ostfeld 1995).

The current consensus regarding equilibriumnonequilibrium dynamics indicates that ecologists have moved past the "either-or" debate and have begun to explore conditions under which both sets of dynamics may arise. As such, there is general agreement that both categories of dynamics potentially operate in ecosystems at various spatial and temporal scales (DeAngelis and Waterhouse 1987; Ellis and Swift 1988; Briske et al. 2003). Illius and O'Connor (1999) illustrated the interaction of equilibrium and non-equilibrium behaviors on the inter-annual dynamics of ungulate populations by describing the involvement of both temporal and spatial scale. They hypothesized that equilibrial dynamics exist between ungulates for only key resource areas within systems during dry years, but that ungulate populations are likely uncoupled from resources within the remainder of the system, especially in normal or high rainfall years. Similarly, a 27-year vegetation record from Sahelian rangelands documented the successive occurrence of equilibrium and non-equilibrium 
dynamics associated with inter-annual rainfall patterns and the associated grazing intensities (Miehe et al. 2010).

The development of non-equilibrial ecology also introduced the concept of ecosystem resilience (Holling 1973). Currently, engineering resilience is used to identify the rate at which an ecosystem returns to its original configuration following disturbance (i.e., homeostasis) and assumes the occurrence of equilibrial conditions (i.e., a single equilibrium point or dynamic regime) (Westman 1985, Holling 1996, Peterson et al. 1998). In contrast, ecological resilience is the pace and magnitude of ecosystem modification that is required before the system begins to reorganize around an alternative set of reinforcing processes (Peterson et al. 1998, Gunderson 2000, Ridolfi et al. 2008, Washington-Allen et al., 2008, Garmestani et al.2009). This interpretation addresses ecosystem behavior as threshold conditions are approached. It further assumes that multiple stable states or equilibrium points exist and that state configuration may irreversibly change when thresholds are crossed.

Although thresholds have attracted a great deal of both theoretical and empirical attention, numerous questions remain regarding their significance, interpretation and identification (Huggett 2005, Briske et al. 2006, Groffman et al. 2006, Biggs et al. 2009, Hasting and Wysham 2010). The inability to satisfactorily, or even partially, answer the following questions emphasizes both the complexity and limited development of the threshold concept. What events or triggers initiate threshold behaviors in various systems? What ecological mechanisms contribute to threshold occurrence? How can pending thresholds be identified and at what point do thresholds initially become irreversible? Do thresholds follow similar developmental trajectories in all ecosystems?

\section{PRIMARY FEATURE THEMES}

\section{Threshold identification and conditions}

Thresholds have been referred to by many synonyms, including critical transitions, tipping points, and discontinuities (Huggett 2005, Washington-Allen and Salo 2007). However, in the context of ecosystem behavior, the following components have broad application: 1) dramatic ecosystem change may result from small changes in conditions or drivers, 2) these changes are not readily reversed by proportional changes to these conditions or drivers, and 3 ) ecosystem resilience is altered as a result of these changes (Scheffer et al. 2001, van Nes and Scheffer 2004). In this context, thresholds represent the conditions at which ecological resilience of the former stable state is exceeded to enable development of an alternative stable state.

The majority of theoretical evidence indicates that non-equilibrium system behavior is not distinguished by unique processes or functions, but rather by evaluation of various temporal and spatial scales within ecosystems (DeAngelis and Waterhouse 1987, Illius and O'Connor 1999). Cross-scale interactions (Gunderson and Holling 2002, Peters et al. 2004) have recently been emphasized as a vital component of resilience in complex systems. Resilience is not determined by a specific system component, but rather by the function those elements provide as well as their distribution within and across scales (Allen et al. 2005). Thresholds may represent discontinuities in controlling processes across or among hierarchical levels as represented by a lack of scale invariance that is complemented by a loss of self-organization (Ludwig et al. 2000, Milne 2000). For example, thresholds at the local spatial scale are constantly shifting in response to more spatially extensive variables and processes (Groffman et al. 2006), but coarse scale dynamics often have limited ability to explain modifications on local sites. Regional or landscape scale thresholds have been hypothesized to occur at the point where coarse scale processes override fine scale processes on individual sites (Peters et al. 2004).

Recent application of analytical procedures to various aspects of non-equilibrial dynamics provides some capacity to quantify patterns and potentially identify early warning signals of catastrophic thresholds. Increasing variability and breaks in autocorrelation of system characteristics and components in time and space (i.e., ecotones) represents a novel assessment of pending threshold occurrence (Allen et al. 2005, Wardell and Allen 2007, Brock and Carpenter 2006, Biggs et al. 2009, Scheffer et al. 2009). The concept of novelty within complex systems, which considers changes in key drivers and self-organizing interactions, will most likely be expressed near shifts or breaks in scale where large fluctuations in resource variability 
increase the success of random events to affect system reorganization (Ludwig et al. 2000, Allen and Holling 2010). Novel events are assumed to have limited opportunity for success far from scale shifts because constant patterns of resource availability are fully exploited (Garmestani et al. 2009).

Discontinuities in animal body mass distributions may reflect discontinuities in scales of environmental structure and processes, and measurement of variability in body mass and associated environmental characteristics over space and time may be indicative of thresholds between two ranges of scale (Allen et al. 1999, Wardell and Allen 2009). Animals possessing body masses that place them in these discontinuities may not be well adapted to the landscape, because there is no ecological structure or resource pattern with which they can interact. Heightened variability of species attributes may approximate thresholds from one set and scale of controlling processes to another. This may be especially true for body mass because is represents an integrative variable that scales allometrically with many ecological attributes (West et al. 1997). Body mass distributions of bird species in the Florida Everglades confirm the hypothesis that variability in population abundance is greater in animal species near the edge of body mass aggregation than it is in species that are situated near the interior of body mass aggregations. This indicates that variability in complex systems may be non-random, and that either heightened or dampened variability may define where shifts in scales of process and structure occur (Milne 2000; Scheffer et al. 2009). Recognition of patterns of variability in species attributes across spatial scales may enhance the effectiveness of monitoring regimes designed to determine the probability of threshold occurrence and the development of alternative regimes (e.g., Kerkhoff and Enquist 2007, Dakos et al. 2009).

Wardwell and Allen (2009), Johnson (2009), and Garmestani and coauthors (2009) demonstrate how empirical evidence of discontinuous distributions within complex systems can be used to disentangle the occurrence of emergent properties including resilience. These authors use analysis of variable discontinuities in time and space to reveal panarchy and interpret pattern in ecological, as well as urban and social systems, to further explain how resilience is generated. This work has contributed to a textural discontinuity hypothesis, which predicts the variability of state variables increases as threshold conditions develop and regime resilience decreases (Wardell and Allen 2009). This emphasizes the importance of panarchy theory in complex systems that contain multiple dynamic regimes nested within larger systems, each of which function at unique scales.

Characteristic length scale (CLS) represents a system-level property that can be estimated from the space-time dynamics of any single component species of an interacting network of species (Johnson 2009). Determination of CLS is accomplished by measuring changes in the magnitude of the prediction error as the scale of observation of species abundance changes, using two error estimates of variance spectra (error X, a scaled error variance) and the prediction $r^{2}$. Novel application of this scaling procedure results from the use of space-for-time substitutions within a limited set of time series data that produces very similar results to more tedious time-series analysis (Johnson 2009). Observation of CLSs are able to distinguish between changes in community structure that reflect 'normal' oscillatory dynamics in phase space (in which case the CLS won't change), and changes in structure that result from fundamental shifts in the nature of the system dynamic (in which case the CLS will change). This procedure may provide a reliable and repeatable means to determine the optimal scale at which to observe the deterministic trend of ecological systems, including catastrophic shifts from one domain of attraction to another.

\section{Threshold interpretation and mechanisms}

Ecological resilience and the associated threshold concept are established on the assumption that the resilience of systems can be exceeded and that these systems can in turn reorganize around a novel set of reinforcing processes (i.e., attractors or equilibrium points). Ecological resilience of stable states can be reduced by improper land use (e.g., fire suppression, soil erosion, and species invasions) and extreme environmental events (e.g., multi-year drought, intense storm events, insect and disease outbreaks), both independently and in combination (Ludwig et al. 2000, Folke et al. 2004, Cumming et al. 2005). Resilience may decrease as a slow imperceptible decline over periods of years and decades that increase the probability of threshold occurrence and the formation of alternative regimes 
(Scheffer and Carpenter 2003). Alternatively, resilience may be exceeded as an abrupt change in ecosystem pattern and process associated with severe episodic events such as 500-year storms or multi-year droughts (Beisner et al. 2003, Walker and Meyers 2004, Washington-Allen et al. 2008, 2009). We advocate that ecosystem management will be most effective if it focuses on maintenance or enhancement of ecological resilience of desirable regimes, because the probability of regime shifts will likely be greater in systems that possess minimal resilience.

Triggers represent variables contributing to the immediate loss of ecosystem resilience and threshold occurrence (Scheffer and Carpenter 2003, Briske et al. 2006). They consist of biotic or abiotic variables or events, acting independently or in combination, that initiate threshold-related processes by shifting the relative strength of balancing (i.e., negative) and reinforcing (i.e., positive) feedback loops (Meadows 2008) that maintain or decrease state resilience, respectively (Wilson and Agnew 1992, Folke et al. 2004). Interactions between these feedback loops contribute to thresholds at the point where ecological function ceases to support the former regime and the system begins to reorganize into an alternative state. The development of alternative regimes following the occurrence of a switch in the relative strength of these feedback loops may be gradually expressed over several decades as resilience of the alternative states continues to increase, but in other cases it may occur rapidly in conjunction with a severe episodic event that imposes a substantial change in regimes (Beisner et al. 2003, Scheffer and Carpenter 2003, Walker and Meyer 2004). The feedback switch interpretation provides a specific description of how ecological processes may contribute to the occurrence of regime shifts in multi-equilibrial systems (Briske et al. 2006, 2008).

\section{Threshold application}

Ecological resilience and the corresponding threshold concept may be referenced as either a heuristic conceptual model to guide and organize thought regarding ecosystem behavior or as an analytical tool to directly implement ecosystem management (Folke 2006). The former perspective has received the majority of attention to date, but attempts to implement the latter perspective are occurring more frequently within applied ecological disciplines to guide natural resource management (Lockwood and Lockwood 1993, 2008). However, capturing the relevance of the threshold concept, within the context of non-equilibrial ecology, requires the development of more effective linkages between theory and application (Bennett et al. 2005, Briske et al. 2006, 2008, Andersen et al. 2008).

As a practical example, the rangeland profession in the United States has adopted non-equilibrial ecology, in the context of the state-and-transition framework, for purposes of promoting rangeland stewardship. State-and-transition models provide a robust framework to evaluate ecosystem dynamics and establish management objectives by accommodating multiple successional pathways and alternative regimes on individual ecological sites (e.g., areas characterized by similar soil, climate and vegetation interactions) (Briske et al. 2005). These models are organized as a collection of alternative stable states that represent the known or anticipated ecosystems that individual ecological sites may support (Westoby et al. 1989, Stringham et al. 2003, Bestelmeyer et al. 2004). This provides ecosystem managers with opportunities to implement adaptive management to avert regime shifts or thresholds, to maintain desirable states, or accelerate regime change in the case of undesirable states. The individual states are separated by thresholds, at least under the constraints of low-input management, which can be induced by natural or human events, independently or in combination. Several federal agencies in the United States have adopted this procedure to monitor and evaluate the ecological condition of rangelands, including those in both public and private ownership. Development of indicators capable of forecasting triggers, changes in feedbacks altering state resilience, scale dependence and cross-scale interactions, and identification of a state's proximity to a pending threshold represents the principle challenge in making this procedure operational (Briske et al. 2008, Biggs et al. 2009, Scheffer et al. 2009).

Management of pests and diseases represents an important application of catastrophe theory and time scale calculus to describe thresholds (Lockwood and Lockwood 2008, Thomas et al. 2009). Knowledge of the population ecology of insects often represents the weakest link in a network of pest management systems (Lockwood and Lockwood 1991, 2008). This makes forecasting insect population dynamics, especially those characterized by 'boom and bust dynamics' over 
vast land areas extremely difficult. Assumptions associated with continuous models may severely constrain these predictions for populations that fluctuate several orders of magnitude within one or more seasons. Non-equilibrium-based models may be a more effective alternative for these applications because they support the investigation of discontinuous phenomena within systems that possess many continuous characteristics (Lockwood and Lockwood 1993). For example, a cusp catastrophe represents the stable manifold of a state variable that arises from two driving parameters. The results of a cusp catastrophe model were consistent with population outbreaks and crashes for different grasshopper species in four ecoregions of Wyoming (Lockwood and Lockwood 2008). This suggests that the widely oscillating dynamics of these grasshopper populations may be based on structural elements of systems where populations are self-structuring in response to external forcing so that small external changes can trigger large changes in populations i.e. self-organized criticality (Lockwood and Lockwood 1997). Results of nonequilibrial models may provide pest managers with tools that more effectively forecast and interpret widely oscillating fluctuations of insect populations.

Spread of West Nile Virus is dependent upon specific vectors and hosts, scales of infection, life histories, incubation, and seasonal affects which complicates disease prediction (Thomas et al. 2009). The virus demonstrates both continuous and discrete behavior in particular state variables that results in a mathematical conundrum in which the solution has been to digitize the continuous signal of differential equations into discrete packets of time, i.e., the use of time scale or invariant calculus. This has resulted in identification of temporal thresholds of mosquito and virus dynamics that inform management solutions to increase the efficacy of disease eradication (Thomas et al. 2009).

Historical remote sensing data, including aerial photography and optical and radar satellite imagery has been used to detect state changes and thresholds of ecological indicators that are proxies of vegetation and soil parameters influenced by livestock grazing and climate change. Representative investigations include use of time series aerial photography and high-resolution satellite imagery in the U.S. Southwest (Laliberte et al. 2004), Western (Barbier et al. 2006) and Southern Africa (Scanlon et al. 2007), and a 30-year time series of Landsat data in the Intermountain region and
Mojave Desert of the US. Finally, radar and aerial photography have been used for similar purposes in the Patagonian Monte shrubland in South America (Ares et al. 2003). Time series of remotely sensed data has been applied to describe ecological indicators of regime shifts and to quantify ecological resilience (Washington-Allen et al. 2006, 2008). Cusp catastrophe theory has been used to develop a framework for evaluating the complex interaction of livestock grazing and soil water availability (two driving parameters) on remotelysensed indicators of vegetation response, physiognomic composition, soil stability, and landscape spatial configuration (Washington-Allen et al. 2006).

Collectively, the investigations discussed in this feature were conducted at large spatial and long temporal scales to support effective application of time series analyses as the dominant statistical analysis technique (Table 1 of Introduction of this feature). A temporal extent of 10 to 25 years and a spatial extent of 1-ha local to national geographic scale and spatiotemporal grain resolutions of 1-yr and $1-\mathrm{m}$ to $60-\mathrm{m}$ may be required to effectively detect threshold dynamics in a number of ecosystems, particularly rangeland ecosystems. Alternatively or in complement, analyses have used space-for-time substitution and simulation models in the absence of long-term data (Lockwood and Lockwood 2008, Johnson 2009).

\section{RESEARCH NEEDS AND PERSPECTIVES}

This synthesis identifies several novel concepts, perceptions, and ecological applications regarding the threshold concept and non-equilibrium dynamics in complex systems. An important contribution of this feature is the convergence of interpretations that have arisen from diverse ecological systems and ecological applications regarding the dynamics of complex systems. Collectively, these interpretations further demonstrate that thresholds and non-equilibrium theory possess inherent value to inform ecosystem managers and policy makers, in addition to providing heuristic conceptual models to organize thought regarding ecosystem behavior (Folke 2006, Scheffer et al. 2009).

Effective application of thresholds to ecosystem management will require development of more 
Table 1. Glossary of ecological terms, concepts and sources used to evaluate nonequilibrium ecology and threshold behavior in ecological systems.

\begin{tabular}{|c|c|c|}
\hline Term & Definition & Source \\
\hline 1/f noise & $\begin{array}{l}S(f)=\beta f-\alpha, \text { where } S \text { is the signal and } f \text { is the frequency. The } \\
\text { constant } \alpha \text {, is a positive real number. }\end{array}$ & $\begin{array}{l}\text { Lockwood and } \\
\text { Lockwood (2008) }\end{array}$ \\
\hline Alternative Stable States & $\begin{array}{l}\text { A system in which the equilibrium state can be at more than one } \\
\text { distinct value for identical values of the control parameters. }\end{array}$ & Lewontin (1969) \\
\hline Basin of Attraction & $\begin{array}{l}\text { The region around an attractor (equilibrium point or limit cycle) for } \\
\text { which all trajectories lead to the attractor. }\end{array}$ & Holling (1973) \\
\hline Catastrophe Theory & $\begin{array}{l}\text { The analysis of degenerate critical points of potential functions to } \\
\text { describe discontinuous phenomena in normally continuous systems. } \\
\text { Seven elementary catastrophic bifurcations exist with the cusp and } \\
\text { fold being most commonly applied in ecology. }\end{array}$ & Saunders (1980) \\
\hline Cellular Automata & $\begin{array}{l}\text { A discrete model consisting of a grid of cells with each cell } \\
\text { occupying one of a finite number of states. A set of rules } \\
\text { parameterized by the states of the local cells govern the change of } \\
\text { states. }\end{array}$ & Wolfram (1984) \\
\hline Characteristic Length Scale & $\begin{array}{l}\text { Optimum scale at which to monitor a system to establish its } \\
\text { deterministic dynamics. }\end{array}$ & Johnson (2009) \\
\hline Fractal Dimension & $\begin{array}{l}\text { A rough or fragmented geometric shape that can be subdivided in } \\
\text { parts, each of which is, at least approximately, a reduced-size copy } \\
\text { of the whole. }\end{array}$ & $\begin{array}{l}\text { Mandelbrot and Wallis } \\
\text { (1969) }\end{array}$ \\
\hline Nonlinear System & $\begin{array}{l}\text { System in which either or both additivity and homogeneity fail to } \\
\text { hold. }\end{array}$ & Scheffer et al. (2003) \\
\hline Power Law & $\begin{array}{l}\text { A polynomial relationship that exhibits scale invariance, generally } \\
\text { of the form, } f(x)=a x^{k} \text {. Metabolic ecology is based on the power law } \\
\text { relationships of allometry. }\end{array}$ & West et al. (1997) \\
\hline Self-Organized Criticality & $\begin{array}{l}\text { A spatial system in which a substrate can be locally redistributed to } \\
\text { the nearest neighbor patches to propagate further redistribution } \\
\text { resulting in arbitrarily large shifts in substrate. The temporal signal } \\
\text { of self-organized criticality is } 1 / \mathrm{f} \text { noise and the spatial pattern is } \\
\text { fractal. }\end{array}$ & $\begin{array}{l}\text { Lockwood and } \\
\text { Lockwood (1997) }\end{array}$ \\
\hline
\end{tabular}

robust linkages between non-equilibrium theory and application to identify threshold conditions and ecological indicators capable of serving as early warning signals of catastrophic change (Andersen et al. 2008, Biggs et al. 2009, Scheffer et al. 2009). Critical linkages include the role of triggers capable of initiating threshold conditions, identification of reinforcing and balancing feedback loops that determine state resilience, and the developmental trajectories and attributes of potential alternative stable states (Briske et al. 2006, Suding and Hobbs
2009). Implementation of effective theoryapplication linkages has the potential to underpin an operational framework of resilience-based ecosystem management founded upon identification of structural indicators that are correlated with vulnerability or proximity to thresholds, rather than emphasizing threshold identification per se (Briske et al. 2008).

Greater knowledge of critical scales, scaling laws and analytical tools is required to effectively address 
scale-dependent processes because catastrophic thresholds are strongly influenced by scale and multiple cross-scale interactions (i.e., panarchy). This will require that ecosystem managers, policymakers, and researchers explicitly define the spatial and temporal boundaries of interest, because they will be essential in delimiting the analysis of dynamics in complex ecosystems. Recognition that system patterns and processes operate at a distinct range of scales indicates that ecological conditions and drivers that constrain threshold conditions within one spatiotemporal context may be different from a unique set or combination of drivers in another system (Johnson 2009, Garmestani et al. 2009, Allen and Holling, 2010). Therefore, it may be plausible to identify common themes associated with non-equilibrial dynamics of ecosystems, but context and legacy will likely direct application of non-equilibrium theory to natural resource management (e.g., Biggs et al. 2009, Scheffer et al. 2009).

The number and category of ecological systems that are likely to exhibit non-equilibrium dynamics, including thresholds, are only beginning to emerge. However, given that catastrophic thresholds and their consequences have been documented in multiple systems (Scheffer and Carpenter 2003, Folke et al. 2004) and that specific systems may show successive intervals of equilibrium and nonequilibrium dynamics (Miehe et al. 2010), it may be prudent to consider all systems as having the capacity to exhibit non-equilibrium behavior until proven otherwise. Erring in this direction will likely produce fewer undesirable ecological and societal consequences than mistakenly assuming a continuation of equilibrium dynamics as has been done in the past. This feature emphasizes the relevance of thresholds and non-equilibrium dynamics to multiple natural resource management applications and in so doing demonstrates the need for a more comprehensive and integrated ecological framework capable of quantitatively assessing these dynamics at multiple scales to inform management and policy recommendations of optimal management strategies and risk assessments.

Responses to this article can be read online at: http://www.ecologyandsociety.org/voll5/iss3/art37/ responses/

\section{Acknowledgments:}

DRL was supported by NSF grant DGE-0221595 and the USDA-ARS. C.R.J's work was supported by an Australian Research Council Discovery Grant. RWA was funded in part by NSF Biocomplexity Project No. BCS-030846 to HHS and a Faculty Development Grant from the Office of the ViceProvost for Faculty Affairs of the University of Virginia.

\section{LITERATURE CITED}

Allen, C. R., E. A. Forys, and C. S. Holling. 1999. Body mass patterns predict invasions and extinctions in transforming landscapes. Ecosystems 2(2):114-121.

Allen, C. R., L. Gunderson, and A. R. Johnson. 2005. The use of discontinuities and functional groups to assess relative resilience in complex systems. Ecosystems 8(8):958-966.

Allen, C. R., and C. S. Holling. 2010. Novelty, Adaptive Capacity, and Resilience. Ecology and Society 15(3):24 [online] URL: http://www.ecology andsociety.org/vol15/iss3/art24/).

Andersen, T., J. Carstensen, E. HernándezGarcía, and C. M. Duarte. 2008. Ecological thresholds and regime shifts: approaches to identification. Trends in Ecology and Evolution 24 (1):49-57.

Ares, J., H. Del Valle, and A. Bisigato. 2003. Detection of process-related changes in plant patterns at extended spatial scales during early dryland desertification. Global Change Biology 9 (11):1643-1659.

Barbier, N., P. Couteron, J. Lejoly, V. Deblauwe, and O. Lejeune. 2006. Self-organized vegetation patterning as a fingerprint of climate and human impact on semi-arid ecosystems. Journal of Ecology 94(3):537-547.

Beisner, B. E., D. T. Haydon, and K. Cuddington. 2003. Alternative stable states in ecology. Frontiers in Ecology and the Environment 1(7):376-382. 
Bennett, E. M., G. S. Cumming, and G. D. Peterson. 2005. A systems model approach to determining resilience surrogates for case studies. Ecosystems 8(8):945-957.

Bestelmeyer, B. T., J. E. Herrick, J. R. Brown, D. A. Trujillo, and K. M. Havstad. 2004. Land management in the American southwest: a stateand-transition approach to ecosystem complexity. Environmental Management 34(1):38-51.

Biggs, R., S. R. Carpenter, and W.A. Brock. 2009. Turning back from the brink: detecting an impending regime shift in time to avert it. Proceedings of the National Academy of Science USA 106(3)826-831.

Briske, D. D., S. D. Fuhlendorf, and F. E. Smeins. 2003. Vegetation dynamics on rangelands: a critique of the current paradigms. Journal of Applied Ecology 40(4):601-614.

Briske, D. D., S. D. Fuhlendorf, and F. E. Smeins. 2005. State-and-transition models, thresholds, and rangeland health: a synthesis of ecological concepts and perspectives. Rangeland Ecology and Management 58(1):1-10.

Briske, D. D., S. D. Fuhlendorf, and F. E. Smeins. 2006. A unified framework for assessment and application of ecological thresholds. Rangeland Ecology and Management 59(3):225-236.

Briske, D. D., B. T. Bestelmeyer, T. K. Stringham, and P. L. Shaver. 2008. Recommendations for development of resilience-based state-and-transition models. Rangeland Ecology and Management 61 (4):359-367.

Brock, W.A. and S. R. Carpenter. 2006. Variance as a leading indicator of regime shift in ecosystem services. Ecology and Society 11(2):9 [online] URL: http://www.ecologyand society.org/vol11/iss2/art9/

Cumming, G. S., G. Barnes, S. Perz, M. Schmink, K. E. Sieving, J. Southworth, M. Binford, R. D. Holt, C. Stickler, and T. Van Holt. 2005. An exploratory framework for the empirical measurement of resilience. Ecosystems 8(8):975-987.

Dakos, V., E. H. van Nes, R. Donangelo, H. Fort and M. Scheffer. 2009. Spatial correlation as leading indicator of catastrophic shifts. Theoretical
Ecology3:163-174 [online] DOI 10.1007/s12080-0 09-0060-6.

DeAngelis, D. L. and J. C. Waterhouse. 1987. Equilibrium and non-equilibrium concepts in ecological models. Ecological Monographs 57 (1):1-21.

Egerton, F. N. 1973. Changing concepts of the balance of nature. Quarterly Review of Biology 48 (2):322-350.

Ellis, J. E. and D. M. Swift. 1988. Stability of African pastoral ecosystems: alternate paradigms and implications for development. Journal of Range Management 41(6):450-459.

Elmqvist, T., C. Folke, M. Nyström, G. Peterson, J. Bengtsson, B. Walker, and J. Norberg. 2003. Response diversity, ecosystem change, and resilience. Frontiers in Ecology and the Environment 1(9):488-494.

Folke, C. 2006. Resilience: the emergence of a perspective for social-ecological systems analysis. Global Environmental Change 16(3):253-267.

Folke, C., S. Carpenter, B. Walker, M. Scheffer, T. Elmqvist, L. Gunderson, and C. S. Holling. 2004. Regime shifts, resilience, and biodiversity in ecosystem management. Annual Review of Ecology, Evolution and Systematics 35:557-581.

Garmestani, A. S., C. R. Allen, and L. H. Gunderson. 2009. Panarchy: discontinuities reveal similarities in the dynamic system structure of ecological and social systems. Ecology and Society 14(1):15. [online] URL: http://www.ecologyandsoc iety.org/vol14/iss1/art15/.

Groffman, P. M., J. S. Baron, T. Blett, A. J. Gold, I. Goodman, L. H. Gunderson, B. M. Levinson, M. A. Palmer, H. W. Paerl, G. D. Peterson, N. L. Poff, D. W. Rejeski, J. F. Reynolds, M. G. Turner, K. C. Weathers, and J. Wiens. 2006. Ecological thresholds: the key to successful environmental management or an important concept with no practical application? Ecosystems 9(1):1-13.

Gunderson, L. H. 2000. Ecological resilience - in theory and application. Annual Review of Ecology and Systematics 31:425-439.

Gunderson, L. H. and C. S. Holling. 2002. Panarchy: understanding transformations in 
human and natural systems. Island Press, Washington D.C., USA.

Hastings, A. and D. B. Wysham. 2010. Regime shifts in ecological systems can occur with no warning. Ecology Letters 13(4):464-472. [online] doi: 10.1111/j.1461-0248.2010.01439.x.

Holling, C. S. 1973. Resilience and stability of ecological systems. Annual Review of Ecology and Systematics 4:1-23.

Holling, C. S. 1996. Surprise for science, resilience for ecosystems, and incentives for people. Ecological Applications 6(3):733-735.

Huggett, A. J. 2005. The concept and utility of 'ecological thresholds' in biodiversity conservation. Biological Conservation 124(3):301-310.

Illius, A. W. and T. G. O'Connor. 1999. On the relevance of non-equilibrium concepts to arid and semi-arid grazing systems. Ecological Applications 9(3):798-813.

Johnson, C. R. 2009. Natural length scales of ecological systems: applications at community and ecosystem levels. Ecology and Society 14(1): 7. [online] URL: http://www.ecologyandsociety.org/vol14/ iss1/art7/

Kerkhoff, A. J. and B. J. Enquist. 2007. The implications of scaling approaches for understanding resilience and reorganization in ecosystems. BioScience 57(6):489-499.

Laliberte, A. S., A. Rango, K. M. Havstad, J. F. Paris, R. F. Beck, R. McNeely, and A. L. Gonzalez 2004. Object-oriented image analysis for mapping shrub encroachment from 1937 to 2003 in southern New Mexico. Remote Sensing of Environment 93 (2):198-210.

Lockwood, J. A. and D. R. Lockwood. 1991. Rangeland grasshopper (Orthoptera: Acrididae) population dynamics: insights from catastrophe theory. Environmental Entomology 20(4):970-980.

Lockwood, J. A. and D. R. Lockwood. 1993. A unified paradigm of rangeland ecosystem dynamics through the application of catastrophe theory. Journal of Range Management 46(4):282-288.
Lockwood, D. R. and J. A. Lockwood. 1997. Evidence of self organized criticality in insect populations. Complexity 2(4):49-58.

Lockwood, D. R. and J. A. Lockwood. 2008. Grasshopper population ecology: catastrophe, criticality, and critique. Ecology and Society 13(1): 34. [online] URL: http://www.ecologyandsociety.org/ vol13/iss 1/art34/

Ludwig J. A., J. A.Wiens, and D. J. Tongway. 2000. A scaling rule for landscape patches and how it applies to conserving soil resources in savannas. Ecosystems 3:84-97

Mandelbrot, B. B. and J. R. Wallis. 1969. Some long-run properties of geophysical records. Water Resources Research 5(2):321-340.

May, R. M. 1977. Thresholds and breakpoints in ecosystems with a multiplicity of stable states. Nature 269(5628):471-477.

Mayer, A. L. and M. Rietkerk. 2004. The dynamic regime concept for ecosystem management and restoration. BioScience 54(11):1013-1020.

Meadows, D. H. 2008. Thinking in systems: A primer. Chelsea Green Publishing Company, White River Junction, Vermont, USA.

Miehe, S., J. Kluge, H. von Wehrden and V. Retzer. 2010. Long-term degradation of Sahelian rangeland detected by 27 years of field study in Senegal. Journal of Applied Ecology 47 (3):692-700.

Milne, B. T. 2000. Fundamentals of Landscape Organization: Coupled Networks, Thresholds, and Allometry," in Integration of Societal and Landscape Heterogeneity: Problems and Solutions, Proceedings of the 15th Annual Symposium of the U.S. Regional Association and International Association of Landscape Ecology and Second Conference of the Walt Dineen Society, Ft. Lauderdale, Florida, USA.

O'Neill, R. V., D. L. DeAngelis, J. B. Waide, and T. F. H. Allen. 1986. A Hierarchical Concept of Ecosystems. Princeton University Press, Princeton, New Jersey, USA. 
Peters, D. P. C., R. A. Pielke, Sr., B. T. Bestelmeyer, C. D.Allen, S. Munson-McGee, and K. M. Havstad. 2004. Cross-scale interactions, nonlinearities, and forecasting catastrophic events. Proceedings National Academy of Science 101 (42):15130-15135.

Peterson, G., C. R. Allen, and C. S. Holling. 1998. Ecological resilience, biodiversity, and scale. Ecosystems 1(1):6-18.

Pickett, S. T. A. and R. S. Ostfeld. 1995. The shifting paradigm in ecology. Pages 261-278 in R. L. Knight and S.F. Bates, editors. A New Century for Natural Resource Management. Island Press, Washington D.C., USA.

Ridolfi, L., F. Laio, and P. D’Odorico. 2008. Fertility island formation and evolution in dryland ecosystems. Ecology and Society 13(1):5. [online] URL: http://www.ecologyandsociety.org/vol13/iss1/ $\underline{\operatorname{art5/}}$

Saunders, P. T. 1980. An introduction to catastrophe theory. Cambridge University Press, Cambridge, UK.

Scanlon, T. M., K. K. Caylor, S. A. Levin, and I. Rodríguez-Iturbe. 2007. Positive feedbacks promote power law clustering of Kalahari vegetation. Nature 449 (7159): 209-212.

Scheffer, M. 2009. Critical transitions in nature and society. Princeton University Press, Oxford, UK.

Scheffer, M. and S. Carpenter. 2003. Catastrophic regime shifts in ecosystems: linking theory to observation. Trends in Ecology and Evolution 18 (12):648-656.

Scheffer, M., J. Bascompte, W. A. Brock, V. Brovkin, S. R. Carpenter, V. Dakos, H. Held, E. H. van Nes, M. Rietkerk and G. Sugihara. 2009. Early-warning signals for critical transitions. Nature 461(3):53-59. [online] URL: http://www.uu. nl/content/SchefferetalNature2009.pdf.

Scheffer, M., S. R. Carpenter, J. A. Foley, C. Folke, and B. Walker. 2001. Catastrophic shifts in ecosystems. Nature 413(6856):591-596.
Stringham, T. K., W. C. Krueger, and P. L. Shaver. 2003. State and transition modeling: an ecological process approach. Journal of Range Management 56(2):106-113.

Suding, K. N. and R. J. Hobbs. 2009. Threshold models in restoration and conservation: a developing framework. Trends in Ecology and Evolution 24(5):271-279.

Thomas, D., M. Weedermann, L. Billings, J. Hoffacker, and R. A. Washington-Allen. 2009. When to spray: a time-scale calculus approach to controlling the impact of West Nile virus. Ecology and Society 14(2): 21. [online] URL: http://www.e cologyandsociety.org/vol14/iss2/art21/

van Nes, E. H. and M. Scheffer. 2004. Large species shifts triggered by small forces. American Naturalist 164(2):255-266.

Walker, B. and J. A. Meyers. 2004. Thresholds in ecological and social-ecological systems: a developing data base. Ecology and Society 9(2):3. [online] URL: http://www.ecologyandsociety.org/vol9/ iss2/art3/.

Wardwell, D. and C. R. Allen. 2009. Variability in population abundance is associated with thresholds between scaling regimes. Ecology and Society 14(2):42. [online] URL: http://www.ecolog yandsociety.org/vol14/iss2/art42/.

Washington-Allen, R. A., and L. F. Salo. 2007. Meeting review: catastrophic thresholds, perspectives, definitions, and applications. Bulletin of the Ecological Society of America 88(2):219-225. http: //www.esapubs.org/bulletin/current/apr07web pdfs/ print/apr07bulletin meetreview.pdf)

Washington-Allen, R. A., L. F. Salo, D. D. Briske, and H. H. Shugart. 2010. Introduction to special feature on catastrophic thresholds, perspectives, definitions, and applications. Ecology and Society 15(3):38. [online] URL: http://www.ecologyandsoc iety.org/vol15/iss3/art38/.

Washington-Allen, R.A., N. E. West, R. D. Ramsey, D. K. Phillips and H. H. Shugart. 2009. Retrospective assessment of soil stability on a landscape subject to commercial grazing. 
Environmental Monitoring and Assessment 106 101-121. [online] URL: DOI 10.1007/s10661-008 -0661-3.

Washington-Allen, R. A., R. D. Ramsey, N. E. West, and B. E. Norton. 2008. Quantification of the ecological resilience of drylands using digital remote sensing. Ecology and Society 13(1):33. [online] URL: http://www.ecologyandsociety.org/vol13/ iss1/art33/.

Washington-Allen, R.A., R. D. Ramsey, N. E. West, and R. A. Efroymson. 2006. A remote sensing-based protocol for assessing rangeland condition and trend. Rangeland Ecology and Management 59(1):19-29.

West, G. B., J. H. Brown, and B. J. Enquist. 1997. A general model for the origin of allometric scaling laws in biology. Science 276(5309):122-126.

Westoby, M., B. H. Walker, and I. Noy-Meir. 1989. Opportunistic management for rangelands not at equilibrium. Journal of Range Management 42(4):266-274.

Westman, W.E. 1985. Ecology, impact assessment, and environmental planning. Wiley, New York, New York, USA.

Wilson, J. B. and A. D. Q. Agnew. 1992. Positivenegative feedback switches in plant communities. Advances in Ecological Research 23:263-336.

Wolfram, S. 1984. Cellular automata as models of complexity. Nature 311(5985) 419-424.

Wu, J. and O. L. Loucks. 1995. From balance of nature to hierarchical patch dynamics: a paradigm shift in ecology. Quarterly Review of Biology 70 (4):439-466. 